\section{Endoscopic diagnosis of a case of malignant melanoma}

\section{Introduction}

Metastates to small intestine is found up to $60 \%$ cases of melanoma patients on autopsy. ${ }^{1-3}$ We report a case with secondary involvement in stomach diagnosed during upper GI endoscopy with a probable primary site at rectum.

\section{Case Report}

A sixty five year old male presented with history of melena and loss of appetite of two weeks duration. He had irregular bowel habits, mostly having loose motions, with bleeding per rectum at times. But he did not have past history of any chronic illness. Physical examination revealed mild pallor. There was no icterus, abdominal mass or any other abnormality and no history of any previous surgery. Hematological investigation revealed no abnormality except low hemoglobin ( $7 \mathrm{gm} / \mathrm{dl})$.

Upper GI endoscopy showed multiple polypoidal lesions in fundus and proximal body of stomach with central ulceration and blackening (Figure 1). The largest amongst them was of around $3 \times 2 \mathrm{~cm}$ size and small satellite lesions were seen surrounding the larger one. Multiple biopsies were taken for histopathological analysis.

Ultrasonography of abdomen and pelvis revealed a rectal mass. There was no hepatic metastasis or abdominal lymphadenopathy. Patient refused further investigation and went home. The biopsy report of polypoidal lesions from stomach was suggestive of pleomorphic tumor cells with

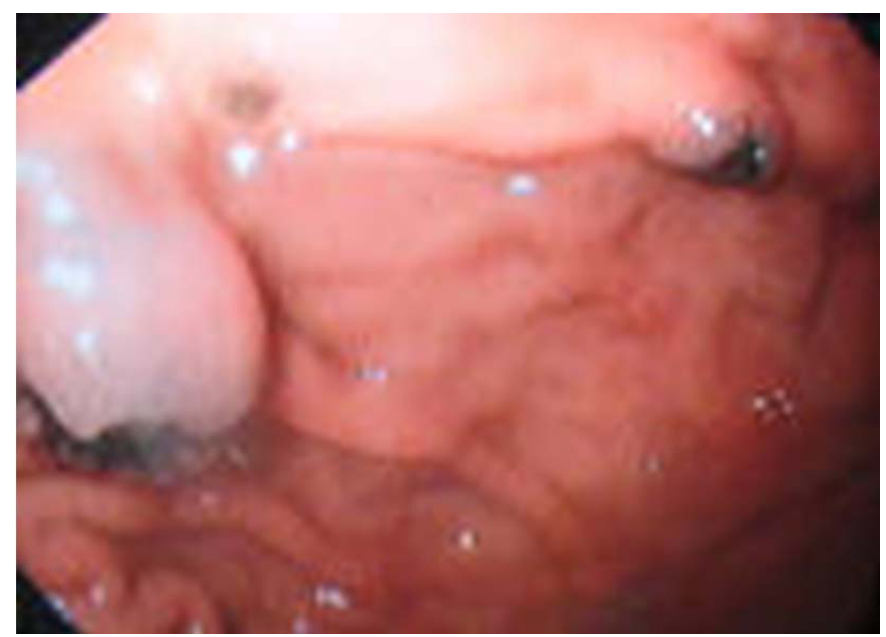

Figure1: Endoscopic picture - stomach having polypoidal lesion with central ulceration and blackening

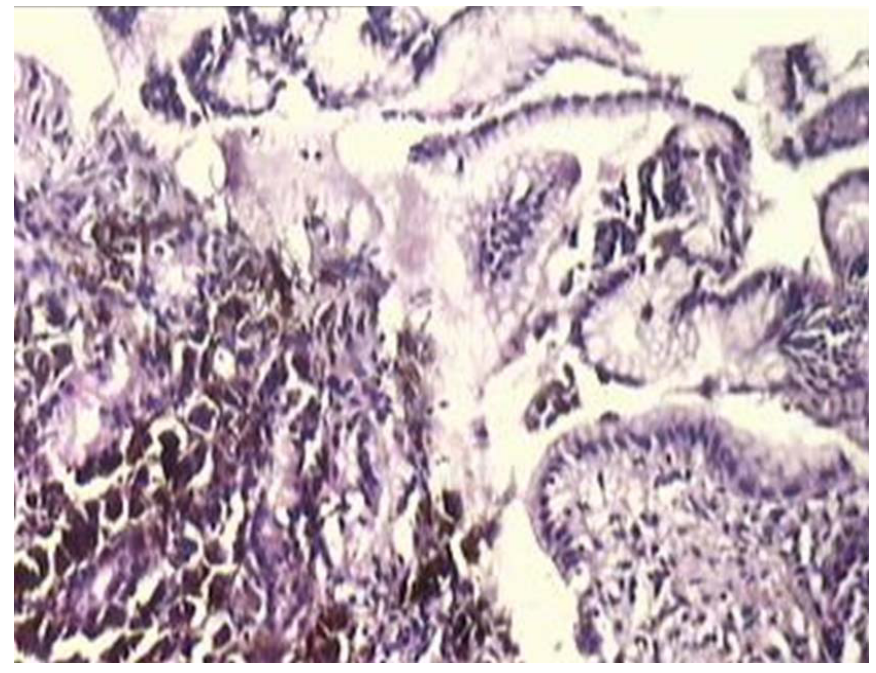

Figure 2: Photomicrograph showing normal gastric epithelium and presence of pleomorphic tumor cells containing dark brown melanin pigment in lamina propria. $\mathrm{H} \& \mathrm{E}$ (x 100)

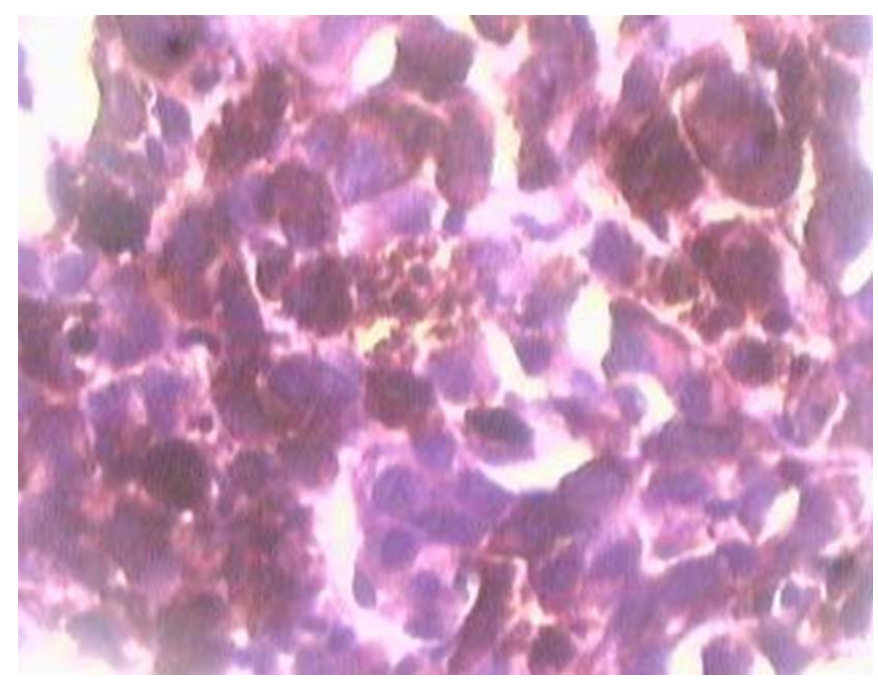

Figure 3: Photomicrograph showing normal gastric epithelium and presence of pleomorphic tumor cells containing dark brown melanin pigment in lamina propria. H \& E (x 400)

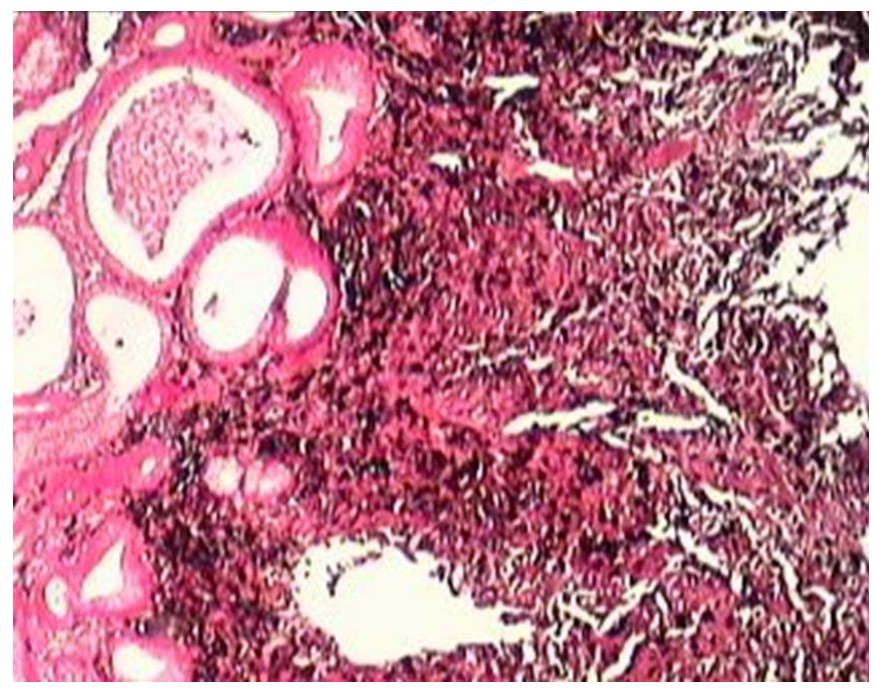

Figure 4: Dark pigments of melanin in tumor cells in lamina propria (Masson- Fontana stain X 100) 
melanin deposits (Figure 2-5). Thus a diagnosis of metastatic deposit of malignant melanoma with a probable site of primary in the anorectum.

\section{Discussion}

Malignant melanoma is an uncommon tumor but is the most common tumor that metastasizes to the gastrointestinal tract. ${ }^{4-}$

6 Endoscopy is a useful diagnostic tool, which may detect various lesions like submucosal nodule, polypoidal mass, gastric ulcer. ${ }^{4}$ Melanotic lesions are common and sometimes the lesion may be amelanotic. Small bowel is the commonest site of GI tract for metastasis. Stomach and duodenum are rare site of metastasis. ${ }^{5,6}$ The presentation of patients also varies from patient to patient. Dyspepsia, GI bleeding, abdominal pain, epigastric mass are some of the common presentations. ${ }^{7}$ Anorectal melanoma is a very rare tumor with poor prognosis. ${ }^{8}$ It is often mistaken for benign conditions such as hemorrhoids or rectal polyp which delays the diagnosis.

H.S. DAS ${ }^{1}$

C. PANDA $^{2}$ $\mathrm{SPADHI}^{2}$ S. P. SINGH ${ }^{1}$

Correspondence: Dr. H.S. Das Department of Gastroenterology $y^{1}$ and Pathology ${ }^{2}$ S.C.B. Medical College, Cuttack 753007, Orissa, India.

Email: hbsrho@yahoo.co.in

\section{References}

1. Frost DB, Mercado PD, Tyrell JS. Small bowel cancer: a 30-year review. Ann Surg Oncol. 1994;1:290-5.

2. Reintgen DS, Thompson W, Garbutt J, Seigler HF. Radiologic, endoscopic, and surgical considerations of melanoma metastatic to the gastrointestinal tract. Surgery. 1984;95:635-9.

3. Backman H. Metastases of malignant melanoma in the gastrointestinal tract. Geriatrics. 1969;24:112-20.

4. Oda, Kondo H, Yamao T, Saito D, Ono H, Gotoda T, et al. Metastatic tumors to the stomach: analysis of 54 patients diagnosed at endoscopy and 347 autopsy cases. Endoscopy. 2001;33:507-10.

5. Liang KV, Sanderson SO, Nowakowski GS, Arora AS. Metastatic malignant melanoma of the gastrointestinal tract. Mayo Clin Proc. 2006;81:511-6.

6. Maladi V, Palanivelu C, Mathew S, Rajan PS, Jani K, Senthikumaran $\mathrm{S}$, et al. Malignant melanoma metastatic to the stomach and duodenum. Indian J Gastroenterol. 2005;24:133.

7. Wysocki WM, Komorowski AL, Darasz Z. Gastrointestinal metastases from malignant melanoma. report of a case. Surg Today. 2004;34:542-6.
8. Biyikoglu I, Ozturk ZA, Koklu S, Babali A, Akay H, Filik L, et al. Primary anorectal malignant melanoma: two case reports and review of the literature. Clin Colorectal Cancer. 2007;6:532-5.

\section{Inflammatory myofibroblastic tumor of gall bladder}

\section{Introduction}

Inflammatory myofibroblastic tumor (IMT) is a very rare low grade malignant tumor with a potential to arise from any organ. Histologically, there is fibrous tissue proliferation without atypia in a back ground of chronic inflammatory cells. Although many hypothesis exist; neoplastic, infectious, reparative, or immunologic, the true etiology of IMT is unclear. ${ }^{1,2}$ IMT of gall bladder is very rare. Only four case reports of IMT of gall bladder are available in literature. ${ }^{3-6} \mathrm{We}$ report a case of IMT of gall bladder in a patient with suspected cancer of gall bladder, who underwent radical cholecystectomy for gall bladder mass lesion.

\section{Case Report}

A 35 year old premenopausal woman presented to the hospital with history of low grade fever (on and off) and dull aching, irregular pain in right hypochondrium (unrelated to food) with occasional radiation to the back and right shoulder since 3 years. On clinical examination, gall bladder was palpable, smooth, firm with rounded margins and moving with respiration. Her hemoglobin was $10.7 \mathrm{gm} / \mathrm{dl}$, serum bilirubin $0.6 \mathrm{mg} / \mathrm{dl}$, AST $32 \mathrm{IU} / \mathrm{L}$, ALT $28 \mathrm{IU} / \mathrm{L}$, ALP $199 \mathrm{IU} / \mathrm{L}$, albumin $4.6 \mathrm{gm} / \mathrm{dl}$. Ultrasonography of the abdomen showed a mass lesion in fundus with a single large stone in gall bladder. Contrast enhanced computed tomography of abdomen and pelvis (Figure 1) revealed a mass lesion in the fundus of gall bladder. The plane with segment $\mathrm{V}$ of liver was ill defined with doubtful invasion of second part of duodenum. There were no significant lymph nodes along the hepatoduodenal ligament, peripancreatic, retroduodenal or celiac axis. She was a resident of Ganga river belt in northern India, which is a high risk region for carcinoma of gall bladder. ${ }^{7}$ With the above history, clinical findings and imaging, a clinical diagnosis of carcinoma gall bladder was made. 